\title{
REVIEW
}

\section{A Literature Review of the Influence of Social Capital on Commercial Credit}

\section{Tixiang Zhou Tinghua Liu* Fengjuan Kou}

School of Economics, Shandong University of Technology, 255000, China

\section{ARTICLE INFO}

Article history

Received: 2 August 2021

Accepted: 6 August 2021

Published Online: 11 August 2021

Keywords:

Social capital

Commercial credit

Informal finance

\begin{abstract}
As a typical informal system, social capital plays an important supplementary role in China's economic transition period. Informal finance based on commercial credit plays a role in the economic cycle. However, there is currently a lack of literature to directly examine the impact of social capital on the use of commercial credit by enterprises. This article aims to systematically sort out the theoretical development of social capital on commercial credit, which mainly includes the definition of social capital, its effects, the influencing factors of commercial credit, and the summary of the existing research results of social capital on commercial credit. It is hoped that this literature review will provide guidance for future research.
\end{abstract}

systems have a broader scope than formal systems and have more lasting vitality. In recent years, the informal system centered on social capital has received more and more attention as an important external environmental factor.

By reading related literature, this article will introduce the current research results through four parts: the definition of social capital, the effectiveness of social capital, the influencing factors of commercial credit, and the influence of social capital on the use of corporate commercial credit.

\section{Definition of Social Capital}

There are a large number of documents explaining the concept of social capital. This article summarizes it from

*Corresponding Author:

Tinghua Liu,

School of Economics, Shandong University of Technology, 255000, China;

Email:haddy1009@163.com 
two aspects: one is the research on social capital abroad; the other is the research on social capital in China.

\subsection{Definition of Social Capital-foreign Research}

Coleman (1988) ${ }^{[3]}$ clearly used the concept of social capital for the first time in sociology and discussed it in depth. Coleman believes that social capital is a social structure resource owned by an individual, that is, an individual's ability to acquire scarce resources in the network or in a broader social structure through their membership. He believes that the main functions of social capital are as follows: 1. Obligations and expectations. When an individual provides services to others, he has social capital, which has the expectation of providing repayable services to others. 2. Information network. Individuals can obtain useful information from the relationships formed by social capital. 3. Standardization and effective punishment. Through the group's conscious resistance to dishonesty behavior, a high-trust social network is formed. 4. Authority relationship, which guides individuals to solve more common problems. Coleman defines social capital from the perspective of functional definition. He points out the role of social capital from multiple angles. His research on social capital is groundbreaking and provides ideas for subsequent research. However, his research also has limitations. He pointed out that social capital is always productive and positive, and denied the possible negative effects of social capital.

Putnam (1993) ${ }^{[4]}$ followed Coleman's point of view. He compared social capital with physical capital and human capital. He believes that social capital refers to the characteristics of social organizations, such as trust, norms, and networks, which can improve the efficiency of the entire society by promoting cooperative behavior between groups. At the same time, he believes that social capital increases the return on investment in physical capital and human capital. Putnam believes that social capital is a close network structure, which is the active participation of citizens in community public activities, and the high level of trust among people caused by this. In his view, the stock of social capital is the level of people participating in club activities in a community. The measurement standards include reading newspapers, participating in voluntary organizations, and expressing trust in political authority. Fukuyama (1995) ${ }^{[5]}$ equates social capital with the degree of social trust, and believes that it is easier for network groups with high trust to develop cooperative relations and bring economies of scale advantages.

LLSV (1997) ${ }^{[6]}$ summarized the research of Coleman
(1990) ${ }^{[3]}$, Putnam (1993) ${ }^{[4]}$ and Fukuyama (1995) ${ }^{[5]}$, and believed that social capital reflects the tendency of cooperation between people in a society. In a society with high social capital, people do not need to consider the "prisoner's dilemma" caused by mutual calculations, but consider enhancing the trust between groups and promoting cooperation between groups to maximize social efficiency.

Portes (1998) ${ }^{[7]}$ made a systematic expression of social capital. He believes that social capital is a collection of actual or potential resources of individuals in social networks. He believes that social capital is related to the individual's membership in the group, and the available resources are related to institutionalized common knowledge and recognized network of relationships. Individuals are not isolated, but through embedding in social network and various connections, and obtain social power, wealth, prestige and other social resources from it.

Lin Nan $(2001){ }^{[8]}$ believes that social capital is a kind of social network resource based on Portes' theory of social resources. Social capital is a resource that individuals mobilize or directly use through their position in the network, and social relations are a type of social capital. The reason why social relations become a resource is because of the imperfection of the market. The information of the market cannot be effectively circulated, and only some people can grasp the information resources.The relationship resources in social networks are not directly occupied by individuals, but directly or indirectly acquired by individuals. Having such resources can enable individuals to better meet their own survival and development needs. The greater the heterogeneity of a person's social network, the higher the status of a member in the social network, and the richer the social resources he has.

\subsection{Definition of Social Capital-domestic Research}

The domestic research on social capital started relatively late, so the research thinking is more influenced by foreign countries. The current research on social capital is basically based on the perspective of obtaining social capital.

Bian Yanjie and Qiu Haixiong (2000) ${ }^{[9]}$, based on the research of foreign scholars, believe that social capital is the connection between the subject and the society and the ability to obtain social scarce resources through this connection. His greatest contribution is to extend social capital from the individual level to the enterprise level. The social contacts and contacts formed by the operators in the daily operation of the enterprise are very important to the enterprise. Therefore, these contacts and contacts 
are also important corporate capital. We believe that it is the social capital of the enterprise. Corporate social capital is an informal mechanism, a bridge for business operators to communicate with the outside world, a channel for establishing business contacts with other companies, and an important way to obtain scarce resources and competition for the market. Bian Yanjie and Qiu Haixiong (2000) ${ }^{[9]}$ divided social capital into horizontal, vertical and social perspectives. The orientation of the vertical angle is mainly upward, and the purpose is to obtain scarce resources from government departments or management. The horizontal angle refers to the connection between a company and other companies. The nature of this connection is diverse, such as a business relationship, a cooperative relationship, a bond-debt relationship, a control relationship, and so on. The social angle reflects the social network brought by the group of business operators living in a specific area.

Zou Yibin (2005) ${ }^{[10]}$ believes that social capital is a kind of network resource, and this resource reflects that the language of mutual help and cooperation has been recognized by the society. In the framework of social capital, social organizations and networks have become important carriers to play this role. People spontaneously establish or participate in certain social organizations, as well as social interactions with relatives, friends and colleagues, etc., to form a certain community-wide social structure and network, so that people have common values, norms of behavior, or mutual affection. Behavior has a stable expectation, that is, it carries the mutual trust between people. Zou Yibin also proposed a more systematic social capital measurement.

Shi Junwei et al. (2007) ${ }^{[1]}$ also believe that corporate social capital is a social network resource, which is the capital obtained through social relations and its network structure, which is basically similar to previous studies. In addition, it also believes that it should include the company's ability to mobilize related resources, which is different from the simple ability to obtain resources. It also refers to companies using social capital to discover resources that may be beneficial to their own development or to occupy the market opportunity. He divided the social capital of enterprises into two categories: one is the social capital of entrepreneurs, and the other is the social capital unique to the organization in the relationship network. Therefore, in his view, the social capital obtained by an enterprise is the result of the overall role of an enterprise. The amount of social capital acquired by an enterprise is the result of the entire organizational factors. It includes not only the joint efforts of entrepreneurs, management and all employees as a regional social group, but also the impact of organizational strength.

\section{Effect of Social Capital}

\subsection{Basic Functions}

Based on existing research, the basic function of social capital is to promote the efficient sharing and dissemination of information, reduce transaction costs, improve the level of cooperation between groups, and consciously resist untrustworthy behavior.

Because the early definition of social capital was put forward based on the definition of social capital's function, the basic functions of social capital formed a certain consensus. Fukuyama (1995) ${ }^{[5]}$ believes that social capital has strong externalities, which can promote cooperation, reduce transaction costs, and make up for the shortcomings of the formal system. Portes (1998) ${ }^{[7]}$ believes that because social capital brings the resistance of social groups to untrustworthy behaviors, which restricts people's behavior. It will also improve the integrity of society as a whole through social morality and public opinion.

Wu Zhiwei (2003) ${ }^{[12]}$ believes that the social network formed through trust and cooperation has established a relatively stable cooperative relationship between members, and the probability of opportunism has been small, which actually reduces the transaction costs between members. Increasing the market opportunities for enterprises can reduce the search costs of enterprises, and at the same time, corporate social capital can cultivate a good market reputation for enterprises, thereby gaining higher recognition of cooperation from other enterprises, and reducing the cost of enterprises to explore the market.

\subsection{Barrier Effect}

The main negative impact of social capital is reflected in its barrier effect.

Portes (1998) ${ }^{[7]}$ was the first to point out the limitations of social capital. He believes that social capital has four negative functions: First, in a group, social capital binds a strong profit relationship between members, and at the same time prevents people from other groups from controlling specific social resources, which leads to new members entering the group. The network has to pay a huge price, which directly reduces the mobility of regional social groups. Second, the closeness brought about by social capital will limit the innovation ability and career development of members, and will adversely affect the development of the region in the long run. Third, the group benefits from social capital, but at the cost of sacrificing and restricting individual freedom, individuals 
generally obey the group and even disappear from the group. Fourth, individuals whose group unity has been consolidated or the suppression of other groups has been stabilized, and who are more capable or innovative.

Domestic scholars also agree that social capital has a barrier effect. Luo Danglun and Tang Qingquan (2009) ${ }^{[13]}$ believe that although social capital brings many benefits to private enterprises, social capital also has negative aspects. Social capital brings strong profit relationships to group members, which actually prevents new groups from obtaining specific social resources. New members have to pay a more expensive price if they want to enter this group. This weakening of liquidity actually reduces the economic efficiency of the region, and it will also cause a lot of unfair competition. Shi Junwei (2007) ${ }^{[1]}$ believes that social capital is a kind of intellectual capital that can explain corporate competitive advantages and optimize management effectiveness. From a competitive point of view, corporate social capital can be a barrier to entry that prevents competitors from grabbing market share.

Chen Jiagui and Wang Qin (2005) ${ }^{[14]}$ believe that under the premise that the market system is not sound and the market credit system is not established, social capital does have an important influence in the region and promotes information exchange. But he also pointed out that social capital has a barrier effect, because the natural closeness and exclusivity of social capital exclude the entry of external resources, which is incompatible with modern large-scale production of socialized information technology. Through his research, he pointed out that the further development of industrial clusters in our country, the exclusive social capital with blood kinship and geographic connections as the bond is strengthening itself, which restricts the inflow of external advanced technology and timely information. Strengthening cooperation between enterprises will also lead to the lack of innovative talents and the low management level. Due to the lack of new information and new technologies within the cluster, the learning effect of the cluster is limited to the simple imitation of the low-level internal members or even stagnation. The industrial clusters brought about by this social capital will directly lock the innovation capabilities and industrial networks of enterprises and weaken the competitiveness of the entire cluster in the long run.

\subsection{Economic and Financial Effects}

Social capital also plays an important role in regional economic growth and corporate financing operations.

Yan Chengliang (2012) ${ }^{[15]}$ believes that social capital has a significant role in promoting economic growth. Social capital has a virtuous circle. The higher the social capital, the more important the social capital is, and more resources will be invested to accumulate social capital. An increase in the level of social capital will improve the efficiency of production and research and development of enterprises, and enterprises will choose to hire more staff to promote economic growth.Liu Fengwei (2009) ${ }^{[16]}$ believed that social capital improved the efficiency of the economy. In regions with high levels of social capital, trust and cooperation among citizens can effectively reduce transaction costs caused by information asymmetry. These advantages promote the efficient operation of the regional economic system. Zhou Jin et al. (2018) ${ }^{[17]}$ found that social capital has a significant positive effect on the quality of economic growth, and its effect is mainly that it significantly improves the efficiency and sustainability of economic growth, while it has an inhibitory effect on growth stability. The longterm effect of social capital is significantly stronger than the short-term effect. Social capital not only has a direct effect on the quality of growth, but also has an indirect positive effect through technological innovation and financial optimization. Foreign scholar Guiso et al. (2004) ${ }^{[18]}$ believe that social capital promotes regional economic development by promoting financial development.

Social capital also affects the financial investment and financing business of enterprises. Pan Yue et al. (2009) ${ }^{[19]}$ believe that social capital affects the investment decisions of enterprises. He explained his point of view from two aspects. On the one hand, in areas with higher levels of social capital, the trust between individuals is higher, and investors therefore trust others more and are therefore more willing to increase investment; on the other hand, On the one hand, because of the higher level of social capital in the region, the degree of trustworthiness of the enterprise is also higher, the investee is also more likely to be recognized by the capital market, and it is easier to reach cooperation with the investor. At the same time, social capital affects corporate debt financing activities. Adler and Kwon (2002) ${ }^{[20]}$ believes that people in areas with high social trust are more inclined to cooperate, borrowing funds will be easier, borrowing periods will be longer, and borrowing costs will be relatively low.Xiao Zuoping and Zhang Ying (2014) ${ }^{[21]}$ found that social capital has an important influence on bank loan interest rates, loan amounts, loan terms, and loan guarantees. Existing studies believe that there are three main reasons for this impact: 1 . Areas with higher levels of social capital have developed social networks, higher information circulation efficiency, and more transparent information about borrowing companies. This reduces the search and supervision costs caused by information 
asymmetry, and eases the moral hazard afterwards (Petersen and Rajan, 1994) ${ }^{[22]}$. 2. The higher the density of the social network, the higher the trustworthiness of the lending bank or credit company to the borrower, so it can provide the borrower with more loan amount, more favorable loan conditions and fewer mortgage guarantees. 3. Enterprises are also willing to use lower-cost debt financing. In areas with higher levels of social capital, corporate management is also more willing to actively use debt to convey the willingness to accept debt constraint supervision to the outside world.

Wei Shouhua (2002) ${ }^{[23]}$ found that the advantageous role of social capital in economics and finance is to cultivate capitalist resources, promote trust-based cooperation, and increase the openness of regional corporate culture. Social capital is an advanced factor of production, which can provide a large number of entrepreneurial resources. Due to geographical proximity, trust-based cooperation between enterprises can reduce transaction costs and improve cooperation efficiency. The interconnections between enterprises, such as contracting, subcontracting, product quality, delivery time, and settlement of funds, are themselves based on trust. Repeated cooperation to avoid opportunistic tendencies is conducive to the establishment of social networks based on trust and commitment between enterprises, reducing transaction costs through network relationships, and strengthening mutual cooperation. The development of corporate culture reflects the free flow of talents and information, and promotes the gathering of all kinds of talents, information, and technology.

Wu Chaopeng (2009) ${ }^{[24]}$ summarized the two major mechanisms of social capital in the economic and financial fields: First, social capital promotes trust and cooperation between individuals, especially strangers, establishes expectations of trustworthy behavior of transaction parties, and promotes corporate financial Cooperation in the field. Second, by improving people's level of integrity, social capital triggers the group's spontaneous resistance to untrustworthy behavior, which can reduce opportunistic behavior and moral hazard in the execution of commercial contracts, so that contracts can be effectively executed.

\subsection{Alternative Protection Effect}

Allen et al. (2005) ${ }^{[25]}$ put forward the famous "China Mystery", that is, China's legal system is very imperfect, but its economic growth is very strong. This is contrary to the theory of coordinated development of law and economy. Therefore, they believe that China has an alternative protection mechanism for the legal system. Allen et al. (2005) ${ }^{[25]}$ believe that China's political relationship mechanism and reputation mechanism have played a role in replacing legal protection mechanisms, while Ang et al. (2009) ${ }^{[26]}$ investigated the important role of social capital in attracting foreign investment in hightech enterprises, showing that Social capital is also an alternative mechanism of legal protection.

Chinese scholars have also reached the same conclusion. Bian Yanjie and Qiu Haixiong (2000) ${ }^{[9]}$ believe that in the cycle of economic transformation in my country, some formal systems such as law and finance are not sound enough, and their protective effects on economic development are limited. To a certain extent, social capital can make up for the system that exists in the transition process.Pan Yue et al. (2009) ${ }^{[19]}$ pointed out that in a country like China with relatively incomplete legal protection, social capital is an important mechanism to replace legal protection to promote economic growth.

Dai Yiyi et al. (2009) ${ }^{[27]}$ believe that social capital, as an informal system outside the formal systems of the legal system and economic system, uses the elements of trust, social norms and social networks it contains to subtly influence business managers' behavior. You Jiaxing and Liu Chun (2011) ${ }^{[28]}$ believe that for developing countries like our country where laws are not sound enough and law enforcement efficiency is not very high, social capital as an informal system can make up for the lack and insufficiency of the formal system in the protection of property rights and reduce the company's Operating risks and improve the stability of the company's future cash flow.

Luo Danglun and Tang Qingquan (2009) ${ }^{[13]}$ analyzed this alternative protection mechanism from the perspective of motivation. Through the investigation of the institutional environment for private entrepreneurs to participate in politics, it is found that the weaker the regional legal system, the stronger the administrative intervention, and the lower the level of financial development, the more motivated private listed companies to form political relations with the government. The reason is that this kind of political relationship is an alternative protection mechanism to the imperfect and imperfect formal system for private listed companies.

Xiao Zuoping and Zhang Ying (2014) ${ }^{[21]}$ analyzed the substitution mechanism of social capital from a game perspective. If the legal rights of creditors cannot be effectively protected by the formal system due to insufficient laws, the importance of social capital will become prominent. Because social capital punishes untrustworthy behaviors to allow traders to comply with the contract as much as possible, reduces the risk of default, and promotes the performance of financial 
contracts. Therefore, social capital plays a role of alternative protection.

\subsection{Diminishing Role Mechanism}

Although there is an alternative protection mechanism for social capital, existing research believes that the strength of this mechanism has been continuously weakened as the marketization process advances.

The theory of "power transfer/elite regeneration" (Szelenyi, 1978; Nee, 1991) ${ }^{[29]}$ believes that the advancement of the marketization process will change the existing power structure, and the original redistributionbased mechanism and elite status will gradually decline. In the wave of marketization, new stratification mechanisms and new elites will appear. This theory also pointed out earlier that the role of social capital in the process of marketization will be weakened. Stiglitz (2000) ${ }^{[30]}$ pointed out the inverted U-shaped relationship between the intensity of social capital and the level of social development. In the early stage of marketization, the scale of the market economy was small and the formal system was imperfect. Social capital as the core of the informal system made up for the shortcomings of the existing market system and dominated the operation of production factors. With the advancement of marketization and the improvement of formal systems, the original dominance of social networks based on trust and cooperation has been impacted. Mature legal systems and official policies have gradually become the main factors that maintain the smooth operation of the market. The value of social networks Will also drop.

Pan Yue et al. (2015) ${ }^{[31]}$ analyzed the mechanism of social capital and government intervention affecting the efficiency of inter-regional capital allocation and conducted empirical tests and found that: a higher level of social capital and a lower degree of government intervention help to improve the efficiency of capital allocation; There is an alternative relationship between social capital and government intervention in affecting the efficiency of capital allocation. In areas where government intervention is more serious, the impact of social capital on the efficiency of capital allocation is more significant. His research also pointed out that the strength of social capital will be weakened with the process of marketization.Xu Yekun and Li Weian (2016) ${ }^{[32]}$ also pointed out that social capital is constantly weakening with the improvement of formal systems. He used social capital data and Fan Gang's marketization index to confirm the legal substitution relationship of corporate debt financing. Research has shown that in areas with a poor legal environment, social capital has a more obvious impact on the debt financing of private enterprises, and with the improvement of the legal system, the role of social capital will be gradually weakened. Yang Xingquan et al. (2021) ${ }^{[33]}$ also found that the legal system and social capital have an alternative relationship, and social capital in areas with a lower level of legal protection can inhibit enterprises from becoming virtual. In regions with a low level of marketization, the problem of information asymmetry is more serious, and social capital has eased the external agency problem of foreign investment, and companies are more willing to increase investment. However, with the increasing transparency of market informatization, the gap between the information obtained through social capital and the direct market access is getting smaller and smaller, and the motivation of enterprises to invest with the advantage of social capital will continue to weaken.

Luo Danglun and Tang Qingquan (2009) ${ }^{[13]}$ pointed out that with the development of the regional private economy, the weight of the private economy in the economy continues to increase, and the private economy has a more urgent need for some policy resources than stateowned enterprises. Actively responding to legal failures, direct participation in politics through participation in people's congresses and CPPCCs at all levels, and the pursuit of formal institutional arrangements in the external environment also means reducing dependence on informal institutions such as social capital.

\section{Factors Influencing Commercial Credit}

The current research on the factors affecting the use of commercial credit by enterprises is mainly divided into two perspectives: the status of the enterprise itself and the external environment.

\subsection{Enterprise's Own Situation}

The research on the company's own conditions is mainly based on the company's internal control quality and market position.

The financial data and internal governance of an enterprise affect the acquisition of commercial credit of an enterprise. According to Zheng Jun (2016) ${ }^{[34]}$ from internal control analysis, companies with higher internal control quality can obtain more commercial credit financing, because the higher the audit quality, the easier it is for the parties to the transaction to form a trust relationship, and they are more inclined to use lower-cost commercial credit. Fabbri and Klapper $(2016){ }^{[35]}$ pointed out from the company's market position that market position affects the acquisition of commercial credit. The 
more customers with negotiation advantage, the more commercial credit they enjoy.

The provision of corporate commercial credit is more affected by corporate financial data and the nature of property rights. Zhang Tiezhu and Zhou Hong (2009) ${ }^{[36]}$ believe that in order to reduce storage costs and promote sales, listed companies with higher inventory levels will adopt looser credit policies to provide more commercial credit.Xu Xiaoping and Li Meng (2009) ${ }^{[37]}$ found that the smaller the scale of enterprises, the more commercial credit they provide. Yu Minggui and Pan Hongbo (2010) ${ }^{[2]}$ researched that enterprises with different property rights make enterprises face different competitive pressures, and private enterprises usually provide more commercial credit than state-owned enterprises.

\subsection{External Environment}

The external environment of the enterprise also affects the use of commercial credit by the enterprise. Formal systems such as law, finance, and monetary policy all affect the financing and operation of enterprises.

The external environment for enterprises to use commercial credit includes monetary policy, degree of marketization, and legal environment. Monetary policy affects corporate investment, investment, and cash holdings (Zhu Jigao and Lu Zhengfei, 2009) ${ }^{[38]}$, which in turn affects corporate business credit. The higher the degree of marketization, the more commercial credit financing a company can obtain, and commercial credit financing has significantly improved the company's business performance and market performance (Cao Xiang and Kuang Xiaoping, 2013) ${ }^{[39]}$. Qian Xuesong and Fang Sheng (2017) ${ }^{[40]}$ studied the reform of the security real right system and found that formal systems promote enterprises to obtain commercial credit.

The external environment for enterprises to provide commercial credit includes economic situation, finance, law, etc. The uncertainty of economic policy affects the provision of commercial credit by enterprises, and the increase in uncertainty of economic policy will significantly reduce the provision of commercial credit by companies (Chen Shenglan and Liu Hongling, 2018) ${ }^{[41]}$. The level of financial development is an important external factor that affects the provision of commercial credit. In areas with better financial development, companies can more easily obtain bank loans, and thus have more funds to provide commercial credit (Yu Minggui and Pan Hongbo, 2010) ${ }^{[2]}$. The legal system is an important determinant to ensure the effective operation of the credit market. In areas with a better legal environment, legal protection of creditors and penalties for debtors' default will encourage commercial credit financing providers to provide more commercial credit (Allen et al., 2005) ${ }^{[25]}$.

\section{The Impact of Social Capital on Commercial Credit}

The social capital of an enterprise belongs to the external environmental factors in which the enterprise is located, and it is also an informal system. Commercial credit is an important informal financial model. At present, there are few literature that directly study the impact of social capital on corporate business credit, but some scholars have focused their perspective on the impact of informal institutions on informal finance. The current research mainly focuses on three aspects: the impact of social capital on corporate financing, the impact of social capital on the substitution effect of bank credit and commercial credit, and the impact of social capital on informal finance through industrial clusters.

The financing ability of an enterprise is an important manifestation of the enterprise's access to social resources, so the social capital of an enterprise is positively correlated with the financing ability of the enterprise. The higher the corporate social capital, the stronger its financing (loan) ability. Financing is the main motivation for companies to use commercial credit, and social capital reduces transaction costs by increasing trust between individuals and strengthening the level of cooperation between parties, thereby promoting the fulfillment of debt contracts. Dai Yiyi et al. (2009) ${ }^{[27]}$ believe that in areas with better levels of social capital, companies are more likely to obtain loans from other members and can use less collateral to obtain debt financing. It believes that social capital is an important informal system that can reduce the probability of various negative problems in financial contracts. Therefore, it is a productive factor. Enterprises can rely on social capital to obtain financial resources such as loans. The dense social interaction network and the binding mechanism of voluntary associations will reduce opportunistic speculation and the phenomenon of "freeriding", and also make individuals pay more attention to the reputation of the company. In such a high-trust area, you can borrow with little or no mortgage assets and rely solely on credit. Mostafa and Ahsan (2019) ${ }^{[42]}$ used US data samples and found that corporate headquarters would benefit from the trust environment brought about by higher social capital in the location, and face a more relaxed financing environment, and therefore need to obtain less commercial credit.

Social capital affects the use of commercial credit 
and bank credit by enterprises. The research of $\mathrm{Xu}$ Yekun and Li Weian (2016) ${ }^{[32]}$ is from the perspective of the substitution effect of commercial credit on bank credit. He believes that social capital affects the source of corporate debt, and different levels of social capital affect the choice of corporate financing methods. In areas with abundant social capital, the amount of bank loans in private enterprise debt financing is relatively small, while the proportion of commercial credit is relatively high. Commercial credit can replace limited bank credit resources.

Social capital influences the use of commercial credit by enterprises through the industrial cluster network. Wang Yue and Liu Ke $(2008){ }^{[43]}$ pointed out that informal systems promote the formation of regional cluster network relationships. This kind of agglomeration effect built on trust among entrepreneurs promotes the use of informal finance among enterprises, and finally drives the entire industry. Qian Shuitu and Weng Lei (2009) ${ }^{[44]}$ pointed out that multi-party interrelated transactions in an industrial cluster can further strengthen the mutual trust generated by long-term continuous transactions. On the one hand, the informal internal information of the enterprise is shared through the cluster network to reduce the cost of obtaining information; On the other hand, through the social punishment mechanism based on consciously resisting breach of contract to strengthen the cooperative relationship of enterprises within the cluster, the society forms a social capital mortgage mechanism in which personal social capital is used as a substitute for physical asset mortgage. Industrial clusters have in fact strengthened the original local social capital. Through institutional arrangements in the form of informal finance, there has been a benign interaction between social capital and the development of clusters. Enterprises not only rely on informal finance to obtain funds, but more importantly, the social capital hidden in informal finance provides strong support for the development of industrial clusters. As a social resource, social capital provides strong support to the development of industrial clusters through informal financial system arrangements.

\section{Conclusions}

At present, domestic and foreign scholars have done in-depth research on the influence of social capital on the use of commercial credit and have obtained certain research results. However, there are still many shortcomings. For example, most of the commercial credit currently studied only refers to the acquisition of commercial credit. Therefore, in the future, we will learn from the research methods and ideas of the predecessors, based on the research perspective of informal systems on informal finance, and study the influence of social capital on the acquisition and provision of commercial credit by enterprises to provide better guidance for the financing operations of Chinese enterprises.

\section{Funding}

We are grateful for the financial support from Surface Project of "Nature Science Found of Shandong Province" (Project Title: Trade credit and TFP of Shandong Manufacturing Enterprises: a Study from the Perspective of Enterprises and Clusters, No. ZR2020MG037); Key Project of "Shandong University Humanities and Social Sciences" (Project Title: the Mechanism of Trade Credit Influencing Technological Innovation: an Empirical Study of Shandong Enterprises, No. J17RZ005); Surface Project of "Social Science Found of Shandong Province" (Project Title: Study on the Mechanism of Informal Finance Promoting Innovation in Shandong Province, No.19CJJJ23).

\section{References}

[1] Wang Guogang, Pan Deng. Horizontal Financial Reform Empowers Double Economic Cycles [N]. Chinese Journal of Social Sciences, 2020 ,(3).

[2] Yu Minggui, Pan Hongbo. Financial Development, Commercial Credit and Product Market Competition [J]. Management World, 2010 ,(8): 117-129.

[3] Coleman, J. S.Social Capital in the Creation of Human Capital. American Journal of Sociology, 1988 :95-120.

[4] Putnam, R. D. The Prosperous Community. The American Prospect, 1993, 4(13):35-42.

[5] Fukuyama, Francis. Trust: the Social Virtues and the Creation of Properity, Nueva York, The Free Press, 1995.

[6] La Porta, R., Lopez-de-Silanes, F., Shleifer, A., Vishny, R. "Trust in Large Organization", American Economic Review,1997,(87):333-338.

[7] Portes Alejandro. Social Capital: Its Origins and Applications in Modern Sociology[J]. Annual Review of Sociology,1998,(24).

[8] Lin Nan. Social Capital: A Theory of Social Structure and Action[M]. New York: Cambridge Univ. Press, 2001.

[9] Bian Yanjie, Qiu Haixiong. Corporate Social Capital and Its Efficacy [J]. Chinese Social Sciences, 2000, (2): 89-99+207.

[10] Zou Yibin. Social Capital: A Literature Review of Theoretical and Empirical Research[J]. Economic Review, 2005 ,(6): 121-126. 
[11] Shi Junwei, Hu Lijun, Fu Haiyan. The Structure of Corporate Social Capital: an Empirical Study Based on Chinese Listed Companies[J]. China Industrial Economics, 2007, (2): 84-93.

[12] Wu Zhiwei. Research on the Connotation and Function of Corporate Social Capital [J]. Soft Science, 2003, (4-5):19-21.

[13] Luo Danglun, Tang Qingquan. Political Relations, Social Capital and Policy Resource Acquisition: Empirical Evidence from Chinese Private Listed Companies [J]. World Economy, 2009, (4)(7): 84-96.

[14] Chen Jiagui, Wang Qin. Sustainable Development of China's Industrial Clusters and Public Policy Choices[J]. China Industrial Economics, 2005, (9):5$10+33$.

[15] Yan Chengliang. Social Capital, Innovation and Long-term Economic Growth [J]. Economic Research, 2012, 47(11): 48-60.

[16] Liu Fengwei, Li Lin, Xue Yunkui. Trust, Transaction Cost and Business Credit Model [J]. Economic Research, 2009, 44(8): 60-72.

[17] Zhou Jin, Jing Guangzheng, Sui Hongguang. How does social capital improve the quality of China's economic growth?[J].Economic Science, 2018(04):33-46.

[18] Guiso, L.,Sapienza, P., and Zingales, L. The Role of Social Capital Financial Development Ameirean Eeonomie Review,2004,(94).

[19] Pan Yue, Dai Yiyi, Wu Chaopeng, Liu Jianliang. Social Capital, Political Relations and Corporate Investment Decision-making [J]. Economic Research, 2009, 44(11): 82-94.

[20] Adler, P. S., Kwon, S. W. Social Capital: Prospects for a New Concept[J].Academy of Management Review, 2002,(27):17-40.

[21] Xiao Zuoping, Zhang Ying. The Influence of Social Capital on Bank Loan Contracts [J]. Securities Market Herald, 2014 ,(12): 32-40.

[22] Petersen, M. A., Rajan, R. G.Trade Credit:Theory and Evidence[J]. Review of Financial Studies,1997,(10):661-691.

[23] Wei Shouhua. The Dynamic Mechanism and Empirical Analysis of Cluster Competitiveness [J]. China Industrial Economy, 2002,(4): 27-34.

[24] Wu Chaopeng. "How do Countries with Weak Intellectual Property Protection Develop High-tech Industries?-Theoretical and Empirical Evidence from Chinese High-tech Companies", PhD Dissertation, School of Management, Xiamen University, 2009.

[25] Allen, F., Qian, J., Qian, M.Law, Finance, and Economic Growth in China[J]. Journal of Financial Economics, 2005, (77):57-116.
[26] Ang, J., Cheng, Y., and Wu C. "Social Capital, Cultural Biases, and Foreign Investment in Innovation: Evidence from China”,Working paper, Florida State University,2009.

[27] Dai Yiyi, Zhang Junsheng, Zeng Yamin, Pan Yue. Social Capital and Corporate Debt Financing [J]. China Industrial Economics, 2009, (8): 99-108.

[28] You Jiaxing, Liu Chun. Entrepreneur's Social Capital and Cost of Equity Capital from the Embedded Perspective__Empirical Evidence from My Country's Private Listed Companies [J]. China Industrial Economics, 2011, (4)(6): 109-119.

[29] Sze lenyi I. Social inequalities in state socialist redistributive economies[J]. International journal of comparative sociology,1978,19(1-2): 63-87.Nee V.Social inequalities in reforming state socialism: between redistribution and markets in China[J]. American sociological review,1991: 267-282.

[30] Stiglitz, J. E. "Formal and Informal Institutions", in Social Capital: A Multifaceted Perspective, The International Bank for Reconstruction and Development. The World Bank,2000:59-70.

[31] Pan Yue, Wang Yuguang,Xu Ting.Social Capital, Government Intervention and Regional Capital Allocation Efficiency__Evidence from Provincial Industrial Data[J].Audit and Economic Research,2015,30(5):85-94.

[32] Xu Yekun, Li Wei'an. Does Social Capital Affect the Source of Debt of Private Enterprises? [J]. Economic Management, 2016, 38(4): 46-59.

[33] Yang Xingquan, Zhang Fangyue, Yang Zheng. Social Capital and Corporate Financialization: Positive Boost or Negative Restraint [J/OL]. Modern Finance, $2021,(4): 3-17$.

[34] Zheng Jun, Lin Zhonggao, Peng Lin. Can High-quality Internal Control Increase Commercial Credit Financing? _ A Test Based on the Perspective of Monetary Policy Changes[J]. Accounting Research, $2013,(6): 62-68+96$.

[35] Daniela Fabbri,Leora F. Klapper. Bargaining power and trade credit[J]. Journal of Corporate Finance, 2016,41.

[36] Zhang Tiezhu, Zhou Hong. Research on the Influencing Factors of Commercial Credit Provided by Listed Companies[J].Financial and Trade Research,2009,20(03):121-127.

[37] Xu Xiaoping, Li Meng. Provision of Commercial Credit: Evidence from Small and Medium-sized Enterprises in Shanghai [J]. Financial Research, 2009 ,(6): 161-174.

[38] Zhu Jigao, Lu Zhengfei. Monetary Policy, Corporate Growth and Changes in Cash Holdings[J]. Manage- 
ment World, 2009 ,(3): 152-158+188.

[39] Cao Xiang, Kuang Xiaoping. Institutional Environment and the Effectiveness of Commercial Credit Financing $[\mathrm{J}]$. Contemporary Finance and Economics, $2013,(5): 115-128$.

[40] Qian Xuesong, Fang Sheng. Has the Reform of the Security Real Right System Affected the Debt Financing of Private Enterprises? —_Empirical Evidence from the Natural Experiment of China's "Property Law" [J]. Economic Research, 2017, 52(5): 146160.

[41] Chen Shenglan, Liu Xiaoling. Uncertainty of Economic Policy and Company Commercial Credit Sup- ply [J]. Financial Research, 2018 ,(5): 172-190.

[42] Mostafa M. H., Ahsan H. Social Capital and Trade Credit[J]. Elsevier Inc.,2019,(61).

[43] Wang Yue, Liu Ke. Analysis of The Effect of Social Capital on the Financing of Small and Medium-sized Enterprises Under the Condition of Cluster [J]. Modern Finance and Economics (Journal of Tianjin University of Finance and Economics), 2008 ,(2): 56-59.

[44] Qian Shuitu, Weng Lei. Social Capital, Informal Finance and The Development of Industrial Clusters-Zhejiang Empirical Research [J]. Financial Research, 2009,(11): 194-206. 